\title{
Comparison of an immunochemical assay for plasma fibrinogen and a turbidimetric thrombin clotting technique to discriminate hyperlipidaemic patients from healthy controls
}

\author{
M L Knapp, M D Feher, H Carey, P D Mayne
}

\begin{abstract}
Plasma samples from patients attending a lipid clinic $(n=14)$ and healthy control subjects $(n=21)$ were assayed for fibrinogen using an immunochemical method (radial immunodiffusion) and a turbidimetric assay based on the thrombin clotting technique. The patients had significantly higher plasma fibrinogen concentrations than controls by both methods, but there was significant overlap between the two groups when fibrinogen was assayed by the thrombin clotting technique; there was almost complete separation of the two groups using the immunochemical assay. This difference in overlap could not be attributed to the presence or absence of fibrinogen degradation products. These findings may have important implications for the choice of method for determining plasma fibrinogen when assays are used for the assessment of cardiovascular risk. It is recommended that plasma fibrinogen should be assayed by both an immunochemical and a thrombin clotting method.
\end{abstract}

Increased plasma fibrinogen concentration has recently been shown to be an independent risk factor for the development of cardiovascular disease. ${ }^{1-7}$ In diabetic subjects studies have shown an association between increased fibrinogen and microvascular and macrovascular complications. ${ }^{89}$ Numerous methods can be used for the estimation of plasma fibrinogen including thrombin clotting techniques, ${ }^{10-13}$ heat precipitation, ${ }^{14}$ salt precipitation ${ }^{15}$ and immunochemical assay. ${ }^{1617}$

With the aim of establishing a plasma fibrinogen method to be used for risk factor analysis in the routine evaluation of patients we compared the result of fibrinogen assayed by a thrombin clotting technique and by an immunochemical method (radial immunodiffusion) in a group of normal healthy controls and hyperlipidaemic patients.

\section{Methods}

All reagents were analytical grade unless otherwise stated. Thrombin $5000 \mathrm{NIH}$ units/phial was obtained from Rorer Pharmaceuticals, Eastbourne, Sussex. Protamine sulphate was obtained from BDH Ltd, Poole, Dorset. Phosphate buffered saline ( $\mathrm{pH} \mathrm{6.4)}$ was prepared by dissolving $\quad \mathrm{KH}_{2} \mathrm{PO}_{4} \quad(0.91 \mathrm{~g}), \quad \mathrm{Na}_{2} \mathrm{HPO}_{4}$
$(0.47 \mathrm{~g})$, and $\mathrm{NaCl}(8.5 \mathrm{~g})$ in distilled water to a final volume of one litre.

Blood was collected from 14 patients attending the lipid clinic at the Westminster Hospital (mean age 63 years, range $49-73$ years). Five of the patients were receiving treatment for hypertension and nine had clinical evidence of macrovascular disease. All patients were being treated for hyperlipidaemia (by diet and drugs). No patient had diabetes; one patient was a current smoker. Blood was also collected from 21 healthy normolipidaemic laboratory volunteers aged $29-40$ years. None of the volunteers was taking any medication and none had a history of vascular disease. Samples were collected into sodium citrate, $38 \mathrm{~g} / 1$ ( 9 volumes of blood per volume of anticoagulant), and centrifuged at $1000 \times g$ for 15 minutes. The plasma was separated and stored within one hour of collection at $-40^{\circ} \mathrm{C}$ until assay. Samples were analysed within one month of collection.

\section{FIBRINOGEN ASSAY}

Samples for determination of plasma fibrinogen were assayed by an immunochemical method (radial immunodiffusion) and a turbidimetric method based on the thrombin clotting technique. ${ }^{13}$ Samples were thawed at $37^{\circ} \mathrm{C}$ for one hour before assay. No trace of fibrin clot was detectable by visual inspection in any of the samples.

For radial immunodiffusion, commercially prepared "Partigen" plates were used (Hoechst, Hounslow, Middlesex) Behringwerke plasma protein standard was used as calibrant (Behringwerke AG, Marburg, West Germany). The plates were used according to the manufacturer's instructions. The between plate coefficient of variation was $5.0 \%$ at a fibrinogen concentration of $4 \cdot 1 \mathrm{~g} / 1$.

Assay of plasma fibrinogen using the turbidimetric method based on the thrombin clotting technique ${ }^{13}$ was carried out on the Centrifichem 600 Centrifugal Analyser (Baker Instruments, Surrey). Pooled normal human plasma collected into sodium citrate was used as standard. The fibrinogen concentration of this standard $(3.6 \mathrm{~g} / \mathrm{l})$ was assigned by assaying it five times using radial immunodiffusion with the Behringwerke plasma protein standard as calibrant. The clotting reagent contained thrombin (2250 NIH units/1), $\mathrm{Ca} \mathrm{Cl}_{2}(2.5$ $\mathrm{mmol} / \mathrm{l})$, and protamine sulphate $(10 \mathrm{mg} / \mathrm{l})$ in phosphate buffered saline, $\mathrm{pH} 6 \cdot 4$. The thrombin was stored at $-40^{\circ} \mathrm{C}$ as a stock solution of $45000 \mathrm{NIH}$ units $/ 1$ in $25 \%$ (v/v) glycerol and was added to the clotting reagent just before 
use. Briefly, sample $(40 \mu \mathrm{l})$ and diluent $(40 \mu \mathrm{l}$ $\left.\mathrm{H}_{2} \mathrm{O}\right)$ was mixed with clotting reagent $(180 \mu \mathrm{l})$ at an analyser temperature setting of $37^{\circ} \mathrm{C}$. The increase in absorbance at $340 \mathrm{~nm}$ was monitored for between three and 90 seconds and was linearly related to fibrinogen concentration up to at least $7 \mathrm{~g} / 1$. The between assay coefficient of variation was $4.2 \%$ at a fibrinogen concentration of $3.8 \mathrm{~g} / \mathrm{l}$.

ASSAY OF FIBRINOGEN DEGRADATION PRODUCTS

The presence or absence of significant amounts of fibrinogen degradation products in the samples was determined on slides by semiquantitative latex agglutination immunoassay. ("Fibrinostrum", Organon Teknika Corporation, Durham, USA). This assay is specific for the cross-linked D-dimer domain in fibrin. If cross-linked D-dimer domain fibrin derivatives are detected in plasma, it confirms that thrombin was formed and that factor XIII was activated with reactive in vivo fibrinolysis. ${ }^{18} 19$ The detection limit of this assay is $500 \mu \mathrm{g} / \mathrm{l}$ in fibrinogen concentration equivalents.

Analysis of correlation between the two methods for plasma fibrinogen assay was carried out by least squares linear regression. Deming's correction for slope was not applied because Sex/Sx was $<0 \cdot 2 .^{20}$ The $\chi^{2}$ test for $2 \times 2$ contingency tables incorporating a correction for continuity and the Mann-Whitney $U$ test were used to analyse the significance of any differences between the plasma fibrinogen concentrations observed in the two groups of subjects. The $F$ test was used to analyse the significance of any differences in the variance of plasma fibrinogen values between the groups. ${ }^{21}$

\section{Results}

There was a good correlation between the turbidimetric thrombin clotting technique and radial immunodiffusion for plasma fibrinogen assay using the samples from the lipid clinic patients and healthy control subjects (fig 1).

Lipid clinic patients as a group had significantly higher plasma fibrinogen concentra-

Figure 1 Correlation between turbidimetric thrombin clotting technique and radial immunodiffusion for plasma fibrinogen assay. $\mathrm{O} \mathrm{O}=$ healthy control subjects: = hyperlipidaemic patients).

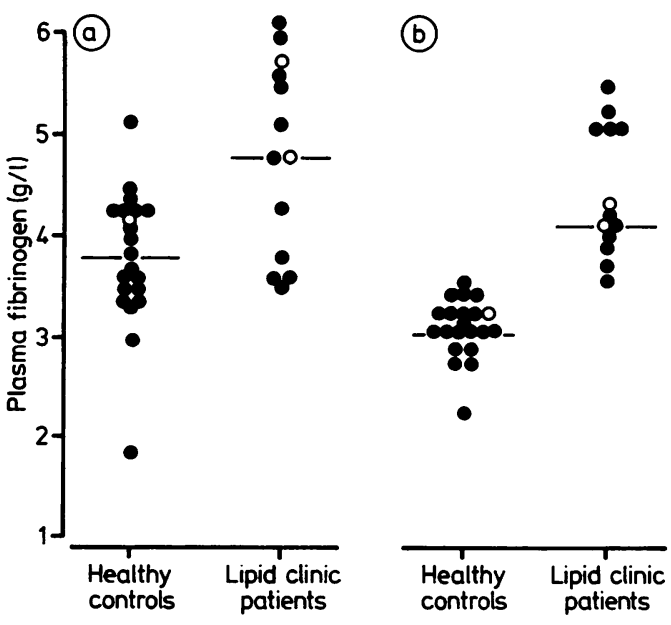

Figure 2 Plasma fibrinogen concentrations in healthy control subjects compared with patients. Fibrinogen assay by (a) turbidimetric thrombin clotting technique; (b) radial immunodiffusion. ( $O)=$ samples containing fibrinogen degradation products; - median concentration.

tions than the healthy control subjects when plasma fibrinogen was assayed either by the turbidimetric thrombin clotting technique ( $p$ $<0.01)$ or radial immunodiffusion $(p<0.001)$ (fig 2).

Optimal discrimination of control subjects from hyperlipidaemic patients was achieved at a cut off of plasma fibrinogen of $4.5 \mathrm{~g} / 1$ for the turbidimetric thrombin clotting technique and $3.5 \mathrm{~g} / 1$ for radial immmunodiffusion. Using these cut off levels, the discrimination of control subjects from patients was significantly better when plasma fibrinogen was assayed by radial immunodiffusion than when measured by the turbidimetric thrombin clotting technique ( $\chi^{2}$ test: $\left.0.02<\mathrm{p}<0.05\right)$. Furthermore, the variance of plasma fibrinogen concentration observed in the control subjects was significantly less using radial immunodiffusion than by the turbidimetric thrombin clotting technique ( $F$ test: $p<0.05$ ), although no significant difference in variance was observed for the lipid clinic patients ( $F$ test: $p>0.05$ ).

Only three out of 35 samples were positive for fibrinogen degradation products by latex agglutination immunoassay; one positive sample was from an apparently healthy control subject and the remaining two positive samples were from the patients. All three samples had fibrinogen degradation products at the limit of assay detection $(500 \mu \mathrm{g} / \mathrm{l})$.

\section{Discussion}

This study has shown that although there is a significant correlation between the turbidimetric clotting technique and radial immunodiffusion for plasma fibrinogen assay, discrimination between hyperlipidaemic patients and a group of healthy control subjects is better by the immunochemical assay. This may have significant implications for the choice of method for plasma fibrinogen when assays are used for the assessment of cardiovascular risk.

It is unlikely that the improved discrimination by radial immunodiffusion can be attribu- 
ted to differences in the amount of in vivo fibrinolysis as only three samples had detectable fibrin D-dimer domain by latex immunoassay. It could be argued that the samples from the patients contained more early fibrinogen degradation products (X, Y, and $\mathrm{E}$ ) which are not detected by the latex immunoassay. If present these products would almost certainly cause overestimation of fibrinogen by radial immunodiffusion because of antigenic cross reaction with the intact fibrinogen molecules. Our data do not support this view, however, because the plasma fibrinogen results by radial immunodiffusion are lower in both healthy controls and hyperlipidaemic patients compared with results using the turbidimetric thrombin clotting technique.

Discrepancies between plasma fibrinogen assay by radial immunodiffusion and the thrombin clotting technique have been previously described following surgery or extensive intravascular thrombosis and during the menstrual cycle. ${ }^{22}$ None of the patients in our study, however, had recently had surgery or extensive intravascular thrombosis. During the menstrual phase, immunoreactive fibrinogen is higher than fibrinogen assayed by the thrombin clotting technique because of the increased concentration of circulating fibrinogen fragments generated by the breakdown of the endometrium. ${ }^{22}$ In our study concentrations of immunoreactive fibrinogen were actually lower than thrombin clottable fibrinogen in both the patient and control groups which makes it unlikely that there were increased amounts of circulating fibrin fragments in our group of patients or controls.

The difference in the median plasma fibrinogen concentrations between the normal healthy controls and hyperlipidaemic patients was similar and was about $1 \mathrm{~g} / 1$. It is the lower variance of fibrinogen values seen in the controls when fibrinogen is assayed by radial immunodiffusion that is the major reason for the improved discrimination between the normal controls and hyperlipidaemic patients when using the radial immunodiffusion assay. It is unlikely that a difference in assay precision could be responsible for this as both methods have similar precision.

Our study needs to be extended to ascertain whether similar discrepancies are observed between immunochemical methods and the clot weight assay ${ }^{12}$ and with heat or salt precipitation. ${ }^{14} 15$ Our results may indicate that the significance of plasma fibrinogen concen- tration as a risk factor for vascular disease may depend on method. Until further work has been carried out, we recommend that for purposes of comparison, plasma fibrinogen should be assayed by both an immunochemical and thrombin clotting method.

We thank Mrs Allison Delamare for performing the analysis of fibrinogen degradation products and Mrs Brenda Zealey for typing the manuscript.

1 Wilhelmsen L, Svardsudd K, Korsan-Bengsten K, Larsson B, Welen $\mathrm{L}$, Tibblin $\mathrm{G}$. Fibrinogen as a risk factor for stroke and myocardial infarction. N Engl J Med 1984; 311:501-5.

2 Stone MC, Thorp JM. Plasma fibrinogen-a major coronary risk factor. $J R$ Coll Gen Pract 1985;35:565-9.

3 Markowe HLJ, Marmot MG, Shipley MJ, et al. Fibrinogen: a possible link between social class and coronary heart a possible link between social class
disease. Br Med J 1985;291:1310-4.

4 Meade TW, Mellows S, Brazovic M, et al. Haemostatic function and ischaemic heart disease: principal results of the Northwick Park Heart Study. Lancet 1986;ii:533-7.

5 Kannel WB, Wolf PA, Castelli WP, D'Agastino RB. Fibrinogen and risk of cardiovascular disease. The Framingham study. JAMA 1987;258:1183-6.

6 Handa K, Kono S, Saku K, et al. Plasma fibrinogen levels as an independent indicator of severity of coronary atherosclerosis. Atherosclerosis 1989;77:209-13.

7 Wiseman S, Kenchington G, Dain R, et al. Influence of smoking and plasma factors on potency of femoropopliteal vein grafts. Br Med J 1989;299:643-6.

8 Barnes AJ. Blood viscosity in diabetes mellitus. In: Lowe GDO, Barbarel JC, Forbes CD, eds. Clinical aspects of blood viscosity and cell deformability. New York: Springer blood viscosity and cell de
Verlag, 1981:105-11.

9 Seviour PW, Rains SGH, Richmond W, Elkeles RS. Plasma fibrinogen and macrovascular disease in non-insulin dependent diabetes. Diabetic Med 1986;3:388A

10 Schneider CL. Rapid estimation of plasma fibrinogen concentration and its use as a guide to treatment of intravascular defibrination. Am J Obstet Gynecol 1952;64:141-7.

11 Ellis BC, Stransky A. A quick and accurate method for the determination of fibrinogen in plasma. J Lab Clin Med 1961;58:477-88.

12 Jacobsson $\mathrm{K}$. Studies on the determination of fibrinogen in human blood plasma. Scand J Clin Lab Invest 1955; 7(Suppl 14):7-54.

13 Denegri E, Prencipe L. Kinetic determination of fibrinogen with a centrifugal analyser. Clin Chem 1982;28:1502-5.

14 Goodwin JF. An evaluation of techniques for the separation and estimation of plasma fibrinogen. Clin Chem 1965; 11:63-73.

15 Rampling MW, Gaffney PJ. The sulphite precipitation method for fibrinogen measurement; its use on small samples in the presence of fibrinogen degradation products. Clin Chim Acta 1976;67:43-52.

16 Farrel GW, Wolf P. Immunonephelometric determination of fibrinogen and its derivatives in plasma. J Immuno Methods 1972;1:217-29.

17 Chen T, Lai CH. Fibrinogen assay by immunodiffusion plate. Am J Clin Pathol 1969;52:629-30.

18 Francis CW, Marder VJ. A molecular model of plasmic degradation of cross linked fibrin. Semin Thromb Hemostas 1982;8:25-35.

19 Hermans J, McDonagh J. Fibrin: structure and interactions. Semin Thromb Hemostas 1982;8:11-24.

20 Cornbleet PJ, Gochmann N. Incorrect least-squares regression coefficients in method-comparison analysis. Clin Chem 1979;25:432-8.

21 Siegel S. Non parametric statistics for the behavioural sciences. London: McGraw-Hill, 1956.

22 Wolf P, Farrell GW, Walton KW. The significance of variations in immunoreactive and clottable fibrinogen in health and following thrombosis. J Clin Pathol 1972; 25:36-44. 